\title{
Sobre lexicografía médica del renacimiento castellano: los vocabularios de Andrés Laguna y Bartolomé Hidalgo de Agüero*
}

\author{
BERTHA M. GUTIÉRREZ RODILLA
}

Universidad de Salamanca

\section{INTRODUCCIÓN}

Como se ha señalado en alguna ocasión (Gómez Moreno 2000: 112), la importancia del léxico de la Medicina no había pasado inadvertida a los principiales intelectuales europeos, en los finales del siglo XV y a lo largo del XVI, lo que les llevó a ocuparse de él en algunas de sus obras. En el caso de nuestro país, los dos ejemplos palmarios los contituirían Antonio de Nebrija - tanto con sus tempranas anotaciones al texto dioscorídeo sobre materia médica como, sobre todo, con su Dictionarium medicum, cuyas entradas se publicaron «entreveradas» con las de su Dictionarium latino-hispanicum (Amberes, 1545) - ; y Andrés Laguna, quien completó su versión castellana del tratado de Dioscórides con unas tablas alfabéticas donde se recogen todos los términos registrados en la obra, en las diferentes lenguas (griego, latín, árabe, castellano...), indicando las páginas concretas donde se encuentran.

Estos trabajos - el Diccionario médico de Nebrija, sus anotaciones a la obra de Dioscórides, la versión castellana de tal obra llevada a cabo por Laguna y los términos incluidos en las tablas multilingües que la completan - han llamado la atención de numerosos investigadores (Carrera de la Red 2001; Dubler 1953-1959; González Manjarrés 2000; Guerrero Ramos 1992, por recordar sólo algunos de ellos), y están suficientemente estudiados y ponderados, lo que le ha valido a sus autores el merecido puesto de honor que ocupan en la historia lexicográfica. Sin embargo, las obras de Laguna y Nebrija a que nos hemos referido dan cuenta escasamente del vocabulario médico o quirúrgico que no sea el de una parte de la terapéutica: están volcadas fundamentalmente — como no podía ser de otra forma, dada su estrecha relación con la

* La investigación necesaria para llevar a cabo este trabajo se ha financiado con las ayudas del Ministerio de Educación y Ciencia FFI2008-03045, al proyecto «Lexicografía y Ciencia. Los repertorios peninsulares de interés lexicográfico-científico...», integrado en la Red Temática «Lengua y Ciencia» (FFI2009-05433-E); y la de la Junta de Castilla y León concedida al GR38, grupo de investigación de excelencia de Castilla y León. 
Materia médica de Dioscórides- sobre las plantas medicinales. ${ }^{1}$ Incluso, el Dictionarium medicum nebrijense, que en principio, no debería su origen a la obra dioscorídea, sigue la misma tendencia y tampoco incluye demasiados términos médicos pertenecientes a otras áreas distintas de la res herbaria, aunque haya algunos; lo que tiene que ver, sin duda, con las fuentes en que se inspiró: Índices del Canon de Avicena, Synonyma medievales, Plinio, etc. (Carrera de la Red 2001: 13-15). ${ }^{2}$

La razón anterior constituye un acicate para buscar otros materiales lexicográficos que puedan existir, aunque puedan no tener la misma entidad - nos referimos, sobre todo, al tamaño- de los ya citados, cuyo análisis nos permita completar nuestro conocimiento de la lexicografía y metalexicografía castellanas del ámbito médicoterapéutico renacentista. En este sentido, es necesario localizar y recuperar los glosarios, vocabularios o cualquier otro tipo de compendio lexicográfico, elaborados en castellano durante el periodo que nos interesa y que aparecieran publicados, no como materiales aislados - pues seguramente ya se conocerían-, sino formando parte de la estructura de otras obras. Este hecho ha determinado que puedan haber permanecido «escondidos», por lo que no se han tomado en consideración para formular hipótesis generales sobre los inicios o el desarrollo de la lexicografía especializada en lenguas vernáculas, ni tampoco para estudiar el léxico especializado de una determinada época. De ahí que sea tan importante identificarlos e irlos añadiendo al corpus de obras y autores, con el fin de afinar cada vez más nuestro conocimiento sobre la historia de la metalexicografía científica, en este caso, la del dominio médico-terapéutico.

De acuerdo con lo que acabamos de decir, en este artículo nos centraremos en dos vocabularios médicos elaborados en la segunda mitad del siglo XVI: el de Andrés Laguna, que se encuentra «escondido» al final de su versión castellana del tratado sobre terapéutica de Dioscórides (Laguna 1555); y el de Bartolomé Hidalgo de Agüero, «escondido» junto a otros de sus escritos, reunidos y publicados siete años después de la muerte del autor, bajo el título Thesoro de la verdadera Cirugía y vía particular contra la común (Hidalgo de Agüero 1604).

\section{LOS AUTORES: El MÉdico hUMANista ANDRÉS LAGUNA Y EL CIRUJANO BARTOLOMÉ HidAlgo de AGÜERO}

Aunque nos lo propusiéramos, no podríamos encontrar dos personas más dispares en sus avatares biográficos y en el desempeño de su profesión: el segoviano Andrés Laguna, conocido como brillante y destacado representante de la medicina del Renacimiento, aunque nace y muere en España (1510-c.1559) pasará la mayor parte de su vida fuera de ella (Francia, Inglaterra, Países Bajos, Alemania, Italia...), participando

\footnotetext{
${ }^{1}$ Para la relación entre Dioscórides y Nebrija, puede consultarse Carrera de la Red (1997).

${ }^{2}$ A título de ejemplo: entre los 323 términos que comienzan por la letra A pertenecientes a dicho diccionario, se encuentran 16 de patología; o, entre los 188 que comienzan por la letra $\mathrm{C}$, se registran 7 de patología, 1 de anatomía y 1 de cirugía, lo que supone en ambos casos menos del 5\% del total, existiendo letras para las que no se incluye ningún término con estas características.
} 
de la llamada «comunidad de los humanistas» y entregado a la tarea que le resultaba más grata: el estudio de los textos clásicos, los ejercicios de crítica textual y la traducción; tarea que compaginaba, cuando podía, con la práctica de la medicina. Publicó numerosas obras, mayoritariamente en latín, como su edición sobre el texto De phisiognomicis, atribuido a Aristóteles; su Anatomica methodus, donde compara la autoridad clásica con los datos obtenidos de la propia experiencia disectiva; la traducción latina del De urinis, atribuido erróneamente a Galeno; tres tratados en latín, uno sobre la gota, otro sobre la peste - que años más tarde aparecería en castellano- y otro sobre dietética en el que recoge consejos médicos para la vejez; los Epitomes omnium Galeni operum, junto a la biografía de Galeno (Vita Galeni Pergameni) y las Annotationes in Galeni interpretes, que constituyen su aportación más significativa al galenismo humanista y la que mayor aceptación y reconocimiento obtendría fuera de la Península, donde quedó eclipsada por el éxito de la traducción del Dioscórides; una obra, también en latín, de contenido quirúrgico, sobre la cauterización de las «carnosidades de la vía de la orina»; un Epitome de los comentarios de Galeno a los textos hipocráticos; unas Annotationes in Dioscoridem, hechas a la versión latina del tratado dioscorídeo que Jean de la Ruelle publicó en 1516; y, desde luego, su traducción castellana de la Materia médica de Dioscórides, el texto sobre terapéutica más importante desde la Antigüedad. ${ }^{3}$

Por su parte, Bartolomé Hidalgo de Agüero (1531-1597), nació, estudió y ejerció la profesión en la ciudad de Sevilla. Allí fue cirujano mayor en el Hospital de San Hermenegildo o del Cardenal, donde alcanzó renombrada fama por los asombrosos resultados obtenidos en sus curaciones, gracias al establecimiento de una nueva vía para el tratamiento de las heridas, que él llamó «particular», de la que ofrece detalles pormenorizados en su escrito Avisos particulares de cirugía contra la común opinión, un pliego impreso en Sevilla en 1584. Su método consistía en tratar las heridas buscando cerrarlas por «primera intención»: tratamiento limpio y suave de las mismas, cosido de los bordes para aproximarlos, aplicación de sustancias secantes y tapado de la herida para resguardarla del contacto con el aire. Este procedimiento se oponía al llamado de «segunda intención», cura húmeda o «vía común» — de ahí que la suya fuera «vía particular»-, acorde con la doctrina galénica y universalmente aceptado y practicado, que consistía en dejar las heridas abiertas hasta que apareciera el llamado pus loable, generado tras usar cauterio y aceite de saúco hirviente. Su actitud innovadora se refleja además en la manera de demostrar las ventajas de su cura frente a la tradicional mediante el análisis de los datos obtenidos de los pacientes del hospital durante más de dos décadas de ejercicio, lo que constituye uno de los intentos más tempranos conocidos de utilización de la estadística hospitalaria (López Piñero 1983: 457). La práctica y difusión de este método «particular»—que siguieron practicando sus discípulos, entre los que se encuentran algunos de los mejores cirujanos españoles de principios del

${ }^{3}$ Son numerosísimos los trabajos publicados sobre la vida y obra de Laguna. Aquí nos hemos servido de la amplísima información que recoge González Manjarrés (2000: 37-139), para ofrecer este pequeño resumen sobre su obra, del que hemos excluido voluntariamente los textos que no son de contenido médico. 
XVII, como Pedro López de León, por ejemplo - le valió a Agüero la admiración y el respeto de los habitantes de Sevilla, que hasta llegaron a considerarlo como un verdadero santo sanador; pero también, agrias críticas y controversias mantenidas con otros cirujanos importantes del momento, como Juan Fragoso, uno de los practicantes de la cirugía más notables de la España renacentista, con el que también disputó a propósito del tratamiento de la sífilis. ${ }^{4}$

Como adelantábamos, sus escritos — que no sólo incluyen estudios de tipo quirúrgico y traumatológico («una de las mejores exposiciones sobre el tema publicadas en la España de la época», López Piñero 1983: 458), sino también breves tratados sobre la peste, el «tabardillo», la «modorra» y la sífilis, así como varios textos anatómicos basados en la disección y de orientación postvesaliana- se reunieron tras su muerte en el Thesoro de la verdadera Cirugía y vía particular contra la común (Sevilla, 1604). No hace falta insistir mucho en el carácter fundamentalmente práctico de la obra de Agüero: estudios quirúrgicos, traumatológicos, textos anatómicos... Y, además, escritos todos ellos en castellano, en la segunda mitad del siglo XVI. Evidentemente el público al que iban destinados no estaba formado por los médicos universitarios, sino por los cirujanos romancistas, barberos o sangradores, algebristas, etc. Es decir, los diversos integrantes del abigarrado grupo de personas que junto a los médicos titulados desempeñaban sus diferentes cometidos profesionales, fundamentalmente de tipo quirúrgico, y no tenían acceso, por las razones que fuera, a la institución universitaria ni, consiguientemente, a las obras en latín. Este hecho los obligó a recurrir a otro tipo de obras para poder completar su formación.

No era ese el público, desde luego, para el que habitualmente escribía Andrés Laguna, prototipo de médico humanista, comprometido con la restauración de los clásicos, para lo que se sirvió de la filología como método indispensable y de la crítica textual, que llegó a dominar con gran pericia (González Manjarrés: 91). Sin embargo, aunque Laguna compuso la práctica totalidad de su obra en latín —así fue hasta 1553 - , sus últimos trabajos los escribe e imprime en castellano. Para tratar de explicar esta preferencia por el romance al final de su obra se han aducido varias razones, relacionadas con el prestigio que algunas lenguas vernáculas adquirieron durante el Quinientos o con el posible retroceso experimentado por el latín como única lengua apta para el intercambio científico en los años transcurridos desde que Laguna inicia su trayectoria profesional hasta que la culmina; pero no se debería descartar que la forma de cumplir el ideal adoptado por buena parte de los humanistas de difundir todo lo posible las obras de los grandes clásicos de la Antigüedad, chocaba con una realidad en la que los médicos con buen conocimiento del latín y del griego eran minoría: razón de peso para traducir los más importantes tratados de los clásicos, también a las lenguas vulgares.

\footnotetext{
${ }^{4}$ Sobre Hidalgo de Agüero, pueden consultarse los trabajos de Castaño Almendral (1959), López Piñero (1983) o Sánchez Granjel (1956). Rodilla (2001).

${ }^{5}$ Vid. estas y otras posibilidades en Gil (1981), González Manjarrés (2000: 261-264) o Gutiérrez
} 


\section{LOS VOCABULARIOS DE LAGUNA Y AGÜERO: CONTENIDO Y RAZÓN DE SER}

A pesar de esas diferencias vitales y profesionales entre nuestros dos autores e independientemente de los motivos que les movieran a componer el resto de sus trabajos, el caso es que ambos — que es lo que aquí nos interesa - acabaron incluyendo un vocabulario de medicina entre sus escritos, con el objeto de favorecer la comprensión a los posibles lectores: el del segoviano forma parte de una serie de instrumentos complementarios, facilitadores de las búsquedas y de la comprensión de la versión castellana del texto dioscorídeo, agrupados al final de la misma. El del sevillano, se encuentra justamente antes de que comience el primero de los tratados que contiene su Thesoro.

El de Andrés Laguna ${ }^{7}$ allega 171 voces médicas —aunque haya algunas que no lo sean, como autumnal, barbarismo, etymologia, frivolo, iberia, quadrangulo o tyrreni$c a$, por ejemplo-, dispuestas de acuerdo con el orden alfabético, bastante bien seguido en general. La información que se ofrece de ellas oscila entre las meras equivalencias y pequeñas perífrasis y las definiciones completas, más o menos elaboradas, como vemos en los siguientes ejemplos:

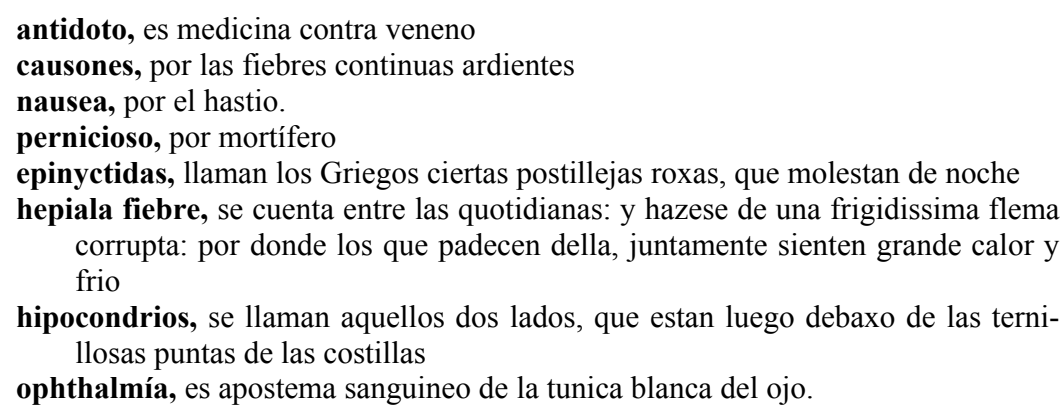

Como cabría esperar, los términos incluidos son mayoritariamente sustantivos con algunos adjetivos y unos pocos verbos- y pertenecen a varias áreas de la medicina del momento, sobre todo, la patología y la terapéutica. Así, encontramos voces del ámbito de la anatomía o de la traumatología (colo intestino, contusion, diaphragma, eminentias, fractura, hipocondrios, musculos, pulmones o ventriculo, por ejemplo). Pero, como decimos, son abrumadoras las de la patología (acrimonia, alopecia, argema, cacochymia, celiacos fluxos, causones, diarrea, estupor, euchymia, ictericos, iliaca passion, entre otras); seguidos de las de la terapéutica (antidoto, apozema, cataplasmas, colyrios, decoccion, diuretico, estiptico, instilar o lenitivo, por ejemplo).

\footnotetext{
${ }^{6}$ Se trata de este glosario de que nos ocupamos, que se acompaña de una tabla de pesos y medidas en castellano, así como de unas tablas, también alfabéticas, donde -como decíamos en la introducciónse recogen todos los términos registrados en la obra en las diferentes lenguas y las páginas donde se encuentran, imprescindibles para que los lectores de diversos países pudieran reconocer con facilidad el simple medicinal descrito. En todo ello queda patente, no sólo el afán de precisión lexicográfica de Laguna, sino su empeño en que la obra le resultara de provecho al mayor número de personas posible.

${ }^{7}$ Blas Nistal hace una descripción de sus principales características (2002).
} 
Parece que el propósito de Laguna a la hora de concebirlo fue esclarecer el significado de algunas palabras en beneficio, no de los médicos universitarios que consultaran la obra, sino de otros posibles lectores — quizá boticarios, cirujanos o el público en general-, pues lo integran, como él mismo lo señala en el prefacio que lo antecede, «algunos vocablos obscuros, y no muy recebidos en nuestra lengua vulgar, ansi Griegos, como Latinos»; vocablos, que aunque podían ser de difícil comprensión tomó por ser propios de la disciplina y le parecieron necesarios para elaborar su discurso «por huir la prolixidad de los circumloquios, pero con intencion de los declarar en el lugar presente, lo qual hare agora, siguiendo el orden del A.B.C» (Laguna, 1555: «Al benigno lector»).

Esas razones debieron ser las mismas que empujaron a Hidalgo de Agüero a confeccionar su repertorio, ya que en el prefacio con que lo inicia dice lo siguiente:

\begin{abstract}
Porque en qualquiera facultad no se puede hablar bien sino es con los terminos del arte, y tambien se deve huyr la prolixidad de los circunloquios, el autor usa algunas vezes de vocablos obscuros assi griegos como latinos, que no estan recebidos los mas dellos en nuestra lengua vulgar. Y porque los cirujanos romancistas, y los demas curiosos pudiessen gozar de la lectura deste libro con facilidad, me parecio ser cosa muy importante allanarles la dificultad que podran tener en la obscuridad de algunos terminos. Y assi van aqui declarados los mas obscuros por orden del A.B.C. (Hidalgo de Agüero 1604: «Al curioso lector»).
\end{abstract}

No hace falta ser muy perspicaces para darse cuenta de que los dos prefacios guardan bastante parecido en algunos puntos (hemos subrayado en negrita las partes idénticas o casi idénticas). Dado que el de Laguna apareció publicado en los años centrales del siglo renacentista y que Agüero debió componer el suyo en el último tercio o cuarto de ese mismo siglo, no parece aventurado suponer que aquel pudiera inspirar a este. Tal idea nos empujó a comparar los términos incluidos en ambos repertorios, para ver hasta dónde alcanzaban las coincidencias, pues quizá Hidalgo no sólo se inspirara en Laguna, sino que se apropiara sin más de los términos de su vocabulario. ${ }^{8}$ Sin embargo, el cotejo de ambos compendios pone de manifiesto que tan sólo una veintena de términos se repite en los dos y tiene una definición idéntica o, al menos, bastante similar: cacochymia, cataplasma, caustico, colyrio, contusion, convulsion, decoccion, diaphragma, disseccion, estiptico, estupor, exhalar, fractura, gangrena, intestino, intestino recto, livido, palpebra y venereo; lo que podría indicar que, efectivamente sí conoció el repertorio del segoviano, pero no pasó de servirle de inspiración y de proporcionarle un modesto $18 \%$ de los términos que allegó en su obra, integrada por 105 voces.

${ }^{8}$ Sobre todo teniendo en cuenta que hay quien le acusa de copiar a otros autores en la composición de sus textos: «El sevillano incisivo no tuvo pudor para saquear la obra de Juan Fragoso [...] y tomar prestados párrafos y capítulos enteros de la Cirugía Universal, que incluyó o se incluyeron en su 'Thesoro de la verdadera Cirugía'» (González Iglesias 1994: 178).

${ }^{9}$ Aunque tal vez no le inspirara, sino que cuando ya tuviera iniciado $-\mathrm{o}$, incluso, terminado- su inventario, cayera en sus manos el de Laguna y le sirviera para completar el suyo, con unos cuantos términos, además del prefacio que tomaría de modelo para redactar el que incluyó en su obra. 
No podía ser de otro modo, dado que el inventario de Agüero estaba fundamentalmente destinado, según nos lo indica en el citado prefacio, a los cirujanos; por lo que, aunque en él se hallan voces de otras áreas de la medicina, las que predominan pertenecen a la anatomía (antrosidad, calvaria, esophago, espondiles, intestino, pericraneo o septo transverso, entre otras), la cirugía (cindente, dilacerada, echymosis, modiolo, perforar, specilo o sutura, por ejemplo), la traumatología (articulo, atrita, contusion, coxendico dolor, fractura, lesion, solucion de continuidad...) y la terapéutica (clyster, decoccion, ectiloticos, enemas, litargirio, locion, meliloto...), lo que confirma el carácter práctico de la obra. Por eso no sorprende demasiado que de los 19 términos que pudo tomar prestados de Laguna, 7 pertenezcan al área de la patología (del total de 12 que incluye de esta área) y 5 al de la terapéutica (de las 15 que allega), los dos ámbitos con mayor peso en el repertorio del segoviano que, por su parte, tienen una importancia menor en el del sevillano.

\begin{tabular}{|l|l|l|}
\hline & LAGUNA & HIDALGO DE AGÜERO \\
\hline patología & $59(34.5 \%)$ & $12(11.4 \%)$ \\
\hline terapéutica & $25(14.6 \%)$ & $15(14.3 \%)$ \\
\hline anatomía & $12(7 \%)$ & $16(15.2 \%)$ \\
\hline traumatología & $3(1.75 \%)$ & $17(16.1 \%)$ \\
\hline cirugía & $3(1.75 \%)$ & $28(26.6 \%)$ \\
\hline $\begin{array}{l}\text { otros (alimentos, pesos y } \\
\text { medidas, lingüistica, etc.) }\end{array}$ & $69(40.3 \%)$ & $17(16.1 \%)$ \\
\hline Número total de voces & 171 & 105 \\
\hline
\end{tabular}

TABLA 1: Distribución por áreas de los términos incluidos por Laguna y Agüero

Unos términos para los que las definiciones que ofrece Agüero, como ocurría en el caso de Laguna, oscilan entre la fórmula sinonímica — la más común - y la perifrástica, siendo frecuente la utilización en ambos casos de fórmulas introductorias en las definiciones del tipo «por», «es», «lo mesmo que», «se dize de», etc., aportándose en

\footnotetext{
${ }^{10}$ A pesar de lo que acabamos de decir, sí da la impresión de que Hidalgo comenzara copiando los términos de terapéutica de forma bastante fiel, pues los 5 de este ámbito que coinciden con los de Laguna pertenecen a las letras C, D y E. En cuanto a los otros 14 términos que podrían proceder de Laguna, justamente la mitad (7), comienza por estas letras C, D y E, mientras que tan sólo 2 proceden de las letras M a la $\mathrm{Z}$. Esto es lo que nos hace pensar que quizá no conociera el texto del segoviano antes de elaborar el suyo, sino que más bien lo usara a posteriori para completar con unos cuantos términos lo que él ya tenía.
} 
unas cuantas ocasiones una definición más elaborada, como vemos en los siguientes ejemplos: 11

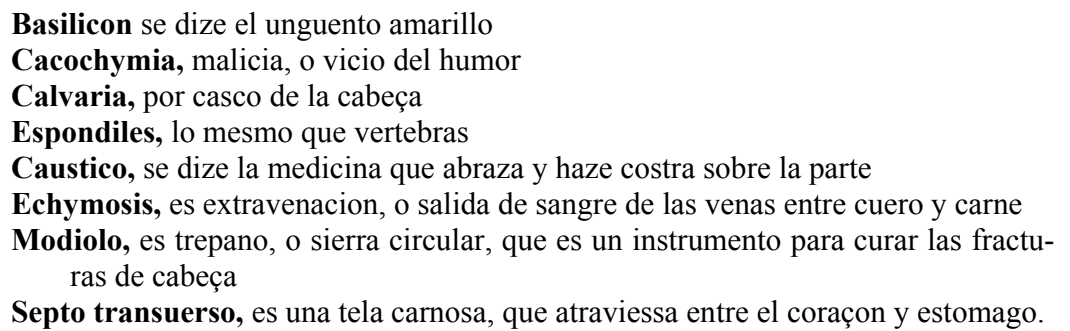

Aunque estamos apuntando que quizá Laguna le sirviera de referente a Hidalgo de Agüero, cabría también la posibilidad de que no fuera así, sino que ambos bebieran de otra fuente lexicográfica anterior. En este sentido, era inevitable que pensáramos en Antonio de Nebrija, el considerado como el lexicógrafo por excelencia de la época que nos ocupa; y, en concreto, en sus trabajos más relacionados con el léxico médico, que citábamos al principio de este artículo: las Anotaciones que le hace al texto sobre materia médica de Dioscórides, que constituyen «un verdadero léxico» (Guerrero Ramos 1992: 7) y su Diccionario médico, bien estudiado por Carrera de la Red (2001). La colación entre estas dos obras y las de Laguna y Agüero arrojan, sin embargo, unos resultados bastante pobres: de las anotaciones de Nebrija a Dioscórides, tan sólo dos términos aparecen en Laguna (alvarazo $(\mathrm{N})$, alvarazos $(\mathrm{L})$ y purpura $(\mathrm{N})$, purpureo (L)) y ninguno en Agüero. Mientras que del Diccionario nebrijense, se encuentran cinco términos en Laguna: alopina $(\mathrm{N})$, alopecia $(\mathrm{L})$; disinteria $(\mathrm{N})$, dysenteria $(\mathrm{L})$; epithema $(\mathrm{N})$, epithimas $(\mathrm{L})$; iliaca $(\mathrm{N})$, iliaca passion $(\mathrm{L})$ y thymos $(\mathrm{N}$ y $\mathrm{L})$; y dos en Agüero: basilicum (N), basilicon (A) y hemorrosagia (N), emorragia (A). ${ }^{12}$ Tampoco esto llama demasiado la atención, si contamos con que los repertorios de Nebrija incluían sobre todo - ya lo señalábamos más atrás — plantas medicinales, acompañadas de algunas otras sustancias animales y minerales empleadas de forma curativa, mientras que los de Laguna y Agüero prácticamente no contienen ninguna - en concreto, el de Laguna, ninguna-. Curiosamente, además, las pocas presentes en Agüero, como meliloto o mille folium, no están en Nebrija. A este respecto hemos de concluir por tanto que, si bien Laguna conoció la obra de Nebrija —e, incluso debió utilizarla en sus trabajos relacionados con Dioscórides (Hinojo 2006: 127) - y siendo probable que Hidalgo la conociera también, no parece que les sirviera de mucho a sus propósitos, seguramente por los distintos ámbitos dentro de la medicina de que querían ocuparse en sus respectivos vocabularios.

\footnotetext{
${ }^{11}$ Presentamos el repertorio de Hidalgo de Agüero en Gutiérrez Rodilla y García Jáuregui (en prensa).

${ }^{12}$ En todos los casos las definiciones son bastante diferentes, por lo que no cabe pensar que Laguna o Agüero las tomaran de Nebrija.
} 


\section{NOVEDAD DE LOS TÉRMinOS ALlegados POR LAGUNA y AGÜERO}

Por otra parte, ambos autores confeccionaron sus compendios — lo decíamos más atrás al referirnos a los prefacios de los mismos-, con el fin de esclarecer el significado de algunos vocablos difíciles «y no muy recebidos en nuestra lengua vulgar, ansi Griegos, como Latinos»; vocablos que podían ser menos comprensibles, suponemos que no para los médicos universitarios, sino para otros posibles lectores como boticarios, cirujanos, sangradores o el público en general. Una manera de intentar averiguar hasta qué punto eran oscuros o novedosos los términos que coleccionaron era compararlos con los recogidos en el DETEMA, elaborado, como se sabe, tomando en consideración textos médicos de finales del medievo, fundamentalmente del siglo $\mathrm{XV}$, aunque se utilizara algún otro más tardío, como el Diccionario de Ruyzes, al que nos referiremos después.

En relación con este punto, hemos encontrado que poco más de la mitad de los términos (el 54\%) del inventario de Laguna se localizan en el DETEMA, con más o menos variaciones gráficas y un significado parecido, subiendo ese porcentaje en Agüero hasta el $62 \%$. A primera vista esto podría indicar que muchos de estos vocablos, a pesar de lo que creyeran los dos médicos renacentistas, podían ya estar insertados en el seno de la lengua al menos desde el siglo anterior. Quizá este fuera el caso de voces como alvarazos, basilicon, cacochimia, contundir, craneo, intestino, perforacion, pericraneo o supurar, por ejemplo. Sin embargo, en el vocabulario que elabora C. Dubler (1953-1959, V), a partir de diversos textos médicos, que se escribieron o se tradujeron al castellano en la última parte de la Edad Media y durante el Renacimiento, de estos nueve términos citados a modo de ejemplo, no se encuentran basilicon, contundir, craneo y perforacion, mientras que las dos únicas fuentes que proporciona para pericraneo y supurar son la obra de Dionisio Daza Chacón (médico y cirujano del XVI) y Juan Alonso de los Ruyzes de Fontecha (médico de finales del XVI y principios del XVII). Por su parte, y en consonancia con lo anterior, Corominas y Pascual (1980-1991) documentan craneo en J. Fragoso, 1580; supurar, en dos autores del s. XVII, mientras que para contundir y perforacion ofrecen los diccionarios académicos del siglo XIX. Es decir, a pesar de que efectivamente aparezcan en el DETEMA, este hecho no siempre debe interpretarse como que tales voces estuvieran plenamente acogidas en la lengua o fueran las más usuales, ni siquiera entre los médicos. De hecho, en algunos casos sabemos con seguridad que había voces, que aunque presentes en el DETEMA, no eran las que con más frecuencia se utilizaban ni en los textos medievales ni aun en los renacentistas, sino otras equivalentes. Así sucedería, por ejemplo, con cataplasma, emorragia, esophago, lesion, podagra o pulmones, con una baja frecuencia de uso frente a sus sinónimas, que eran las predominantes: emplasto, fluxo de sangre, tragadero, daño, gota o livianos.

En cualquier caso, otros varios términos de los seleccionados por Laguna y Agüero podrían considerarse como realmente «novedosos», no incluidos en el DETEMA y que otras fuentes consultadas (Corominas y Pascual 1980-1991; Dicciomed; Dubler 19531959, V; Marcovecchio 1993) o no recogen, o los documentan en el siglo XVI incluidos sus últimos años - y posteriores; con lo que las obras de Laguna y de Agüero 
habrían sido de las primeras de este tipo donde quedaran consignados con sus significados concretos. Este sería el caso de los siguientes ejemplos:

- antrosidad, que no figura en los autores consultados;

- celiaco, que Dubler no menciona; para el que Marcovecchio recoge como primera documentación —en francés-, 1545; Corominas y Pascual, Laguna, 1555; y en Dicciomed la primera documentación se registra en 1560, también en francés; - cindense, término de cirugía no recogido por los autores consultados;

- convulsion, para el que Dubler ofrece documentación en Daza (s. XVI) y Ruyzes (ss. XVI-XVII); en Dicciomed, la primera documentación como término reintroducido para el español es de 1557; en Marcovecchio, 1561; Corominas y Pascual, 1644 ;

- cutis, no aparece en Dubler; para Dicciomed, reintroducida como cultismo, documentada en español en 1591; Corominas y Pascual, principios siglo XVII;

- disseccion, Corominas y Pascual, lo documentan en 1629, en Huerta, a partir de Autoridades; en Dicciomed se explica que es un calco renacentista para traducir el término griego anatomía, que aparece en francés en 1538 y en español en 1594; y Dubler comenta que es un término mucho menos usado por los autores de su corpus, que prefieren anatomía;

- estilicidio de orina (estranguria), que ningún autor recoge, excepto Dubler, que la sola documentación que ofrece es Laguna;

- extravenado, para el que Dubler ofrece documentación en Fragoso (s. XVI) y no incluyen los demás;

- modiolo, no en su acepción de eje central de la coclea o columela, sino como término de cirugía, que - aunque ya descrito por Celso - no está presente en los autores consultados;

- opistotono, solo en Dicciomed se explica que aparece deformado en castellano medieval —aunque no se registre en DETEMA - y que se reintroduce después como forma culta;

- septo transverso, no incluido por los autores consultados, aunque lo utilizaran varios de nuestros anatomistas y cirujanos de la segunda mitad del siglo XVI como equivalente de diafragma;

- sutura, en su acepción quirúrgica de 'cosido' o ‘costura', no en la anatómica 'articulación de ciertos huesos del cráneo'-, que Dubler documenta en Daza (s. XVI), Marcovecchio marca como reintroducido en el XVI; Dicciomed explica que es término reintroducido, documentado en español en 1495 y en francés en 1540; y Corominas y Pascual sitúan a principios del s. XVIII, a partir de Autoridades;

- venereo, Dubler sólo lo documenta en Laguna; Corominas y Pascual, hacia 1440 y también en Laguna, 1555; mientras que Dicciomed recoge que es voz reintroducida en el Renacimiento;

- vertebra, en su acepción de 'hueso de la columna', generalmente conocido en la época como espondil o nudo del espinazo, Dubler lo documenta en Ruyzes (ss. XVI-XVII); Corominas y Pascual en Autoridades; y en Dicciomed se recoge que aunque vertebro ('cabeza del fémur') se documenta en castellano en 1450 , vertebra lo hace un siglo después.

Incluso, hubo algún término como calvaria ('cráneo') por ejemplo, que aunque empleado por varios autores del XVI - Valverde de Amusco, Francisco Díaz o Juan Fragoso, entre otros-, no debió hacer mucha fortuna en castellano en siglos posteriores —sí en inglés-, pues se acabaría sustituyendo por bóveda craneal o cráneo; con lo 
que el repertorio de Agüero, donde sí quedó recogido, se convertiría quizá en el único de este tipo que lo registrara.

Lo que acabamos de exponer creemos muestra de forma bastante clara que, efectivamente, el grado de novedad de los términos de Agüero y Laguna fue bastante alto, lo que además de conferirle a sus repertorios mayor interés, debería haber influido en que encontraran alguna resonancia posterior. En este sentido, no podíamos dejar de comparar los términos y las definiciones allegadas por nuestros autores con las de la colección de voces incluida al final de la obra Diez privilegios para mujeres preñadas del médico Juan Alonso y de los Ruyzes de Fontecha (Alcalá de Henares, 1606), con el propósito, según lo explica su autor, de que «los estudiantes que comiençan la ciencia de la medizina tengan noticia dellos». Esta comprobación era obligada, como decimos, dado que algunos estudiosos (Dubler 1953-1959, V: 118; Nieto Jiménez y Alvar Ezquerra 2007: XXXVI) consideran este repertorio como el primer vocabulario o diccionario español de tecnicismos médicos. A pesar de ello, no esperábamos demasiado de la misma: en el caso de Agüero, porque su obra se publica tan sólo dos años antes (1604) que la de Ruyzes, con lo que hubiera sido muy raro que este último se apoyara en aquel; y, en el de Laguna - aunque también en el de Agüero- porque teniendo en cuenta las fuentes, medievales, de las que se sirve Ruyzes - fundamentalmente la Clavis sanationis de Simón de Génova y los índices de la traducción del Canon de Avicena (Zabía Lasala 1999: XVII-XVIII) - , así como el estilo de su compendio -la procedencia lingüística de las voces que incluye, entre las que sobresalen los arabismos, el predominio de la materia médica, etc.-, era bastante improbable que tuvieran demasiado en común y que en Ruyzes se reconociera la huella de Laguna o de Agüero. El análisis realizado corrobora la falta de coincidencia que intuíamos: a título de ejemplo, de las voces del inventario de Laguna que comienzan por la letra A, únicamente 6 aparecen en Ruyzes; ninguna de las de la B; 4 que empiezan por C; 3 que lo hacen por D... Son valores que en conjunto supondrían menos de un $6 \%$ del total. Un bajo porcentaje que aún sería menor si contáramos con que de estas posibles voces que coincidieran, algunas no se localizan como entradas en Ruyzes, sino en la definición de otras voces, como sucedería, por ejemplo, con albarazo, que se encuentra en la definición de vitiligo, pero que no tiene entrada propia.

En principio, no habría ningún otro repertorio lexicográfico médico con el que poder hacer comparaciones, ya que hasta el momento no se tiene noticia de que se compusieran obras en castellano de este tipo durante el siglo XVII. Y las escasas que lo hicieron durante el XVIII, como la de Joaquín Villalba o la de Francisco Suárez de Rivera, están alejadísimas de las de Agüero y Laguna (por sus características, tipo de

${ }^{13}$ En cualquier caso, en la actualidad se encuentra calvario en algunos artículos médicos, como resultado de una mala traducción del calvaria inglés. No sería de extrañar que en algún momento a alguien se le ocurriera recurrir a nuestros anatomistas del Renacimiento para maquillar y justificar este error de traducción. 
voces incluidas, etc.), por lo que no tiene sentido efectuar el cotejo. ${ }^{14}$ Sí hubo, sin embargo, en el siglo ilustrado una obra en la que el vocabulario de Laguna podría haber quedar perpetuado: nos referimos al conocido Diccionario de Autoridades, dado que en él la autoridad más utilizada para apoyar las voces del ámbito médico fue justamente Andrés Laguna y su versión castellana de la obra de Dioscórides (Gutiérrez Rodilla 1996). A pesar de ello, tan sólo los redactores de las letras A-C y de la S, se sirvieron del inventario que a nosotros nos interesa -al que unas veces citan como índice y otras como tabla-, convirtiéndose este para algunos términos en la única autoridad mencionada. Así, hay una referencia explícita al mismo en las entradas acetábulo (Lag. Diosc. en el índice), para la que se aporta la misma definición del vocabulario («Acetábulo es una medida antigua como una salserita pequeña»); adstriccion («Assi lo dice Laguna en la Tabla que trahe à lo último de su obra de los nombres obscuros y no vulgares de que ha usado en toda ella»); argema («Lag. en la tabla primera del Indice: argema es nube del ojo»); cacochimia («Lag. Diosc. en la tabla de los nombres obscuros. cachochimia es la malicia de los humores»); salubridad (Lag. Diosc. Índic.) y siliqua (Lag. Diosc. Índic.).

\section{A MODO DE CIERRE Y CONCLUSIÓN}

Enlazando con lo que presentábamos en los párrafos anteriores, no parece que fuera excesiva la influencia que las obras estudiadas pudieran dejar sobre otras posteriores; como tampoco ha sido demasiada la atención que les hayan podido prestar los estudiosos ni la valoración que hayan podido hacer de ellas. Sin embargo, si queremos tener una visión más adecuada de lo que pudo ser la práctica lexicográfica especializada en este caso, la del ámbito médico - en siglos pasados, hemos de aprender a incorporar a nuestros análisis nuevos materiales que se vayan encontrando. Unos materiales, que necesariamente nos conducen a matizar nuestras ideas previas sobre esa práctica lexicográfica y nos obligan a ser cautos cuando saquemos conclusiones sobre ella, ya que ponen de manifiesto que no conocemos más que una parte de lo sucedido.

Así, por ejemplo, habrá que aceptar que no solo el humanismo o el interés meramente filológico produjeron frutos lexicográficos interesantes. También entre los médicos que decidieron ocuparse con exclusividad de la práctica quirúrgica - $\tan$ universitarios como los del movimiento humanista - hubo quienes acometieron labores de lexicografía especializada, movidos no por un interés filológico relacionado con la depuración del lenguaje o de restauración de una lengua clásica, sino por un afán instructivo, relacionado con la formación de personas muy concretas. Este sería el caso de Hidalgo de Agüero, cuyo vocabulario es particularmente interesante por los términos

\footnotetext{
32).

${ }^{14}$ Para las características de estas obras del XVIII, puede consultarse Gutiérrez Rodilla (1999: 15-

${ }^{15}$ Lo señalado viene a añadir nuevos datos a los que ya ofrecíamos hace tiempo (Gutiérrez Rodi1la 1996) sobre la forma en que se distribuyeron las letras y el modo de trabajar de los diferentes lexicógrafos que compusieron el Diccionario de Autoridades.
} 
de cirugía, anatomía y traumatología que incluye, raramente presentes en otros repertorios médicos de la época.

Tampoco nos parece un hecho menor el que tanto Nebrija como Ruyzes, los dos grandes referentes hasta ahora considerados cuando se habla de lexicografía médica perirrenacentista en nuestro país, utilizaran como fuentes fundamentales para sus textos los repertorios lexicográficos medievales que citábamos más atrás, de los que bien podrían considerarse continuadores. Algo, que queda patente en el tipo de voces que incluyen, bastante inclinadas hacia la materia médica - obre todo en Nebrija- y en la procedencia de las mismas, muy ligadas a la transmisión árabe - especialmente en Ruyzes - . Todo ello, sin quitarles ningún mérito, le confiere a sus obras un carácter más propio del periodo previo al Renacimiento, pues además la medicina que reflejan está más cercana al galenismo arabizado bajomedieval que al nuevo galenismo humanista europeo.

Ese no parece ser el caso, sin embargo, de Laguna y Agüero, que nos ofrecen en sus vocabularios términos de todas las áreas de la medicina del momento (anatomía, cirugía, patología, terapéutica...), olvidándose — seguramente de forma voluntaria - de la materia médica, estrella indiscutible hasta entonces de todos los repertorios médicos de interés lexicográfico existentes (Gutiérrez Rodilla 2007). De igual manera, el árabe —o los arabismos - no tienen gran representación en estos dos vocabularios, en los que se recogen en cambio numerosos términos - entre ellos, varios cultismos-, cuyo uso se empezaba a imponer a finales del siglo XV y durante el XVI, pudiendo ser para algunos de ellos la primera -0 , incluso, la única - documentación en un repertorio lexicográfico existente. En relación con la lengua, mientras que en el diccionario de Ruyzes las entradas pueden encontrarse en lengua latina, ser transliteraciones del árabe o del griego, términos híbridos (base árabe o griega con sufijo romance), siendo raramente términos romances (Zabía Lasala 1999: XII) y en Nebrija son igualmente una combinación de arabismos, helenismos y latinismos (Carrera de la Red 2001: 15), tanto en Laguna como en Agüero se percibe un intento de que las entradas estén constituidas por términos romances, a pesar de que alternen con voces de otro origen, que sólo excepcionalmente, como decimos, es el árabe.

Por otro lado, el modo de definir de que sirvieron Nebrija o Ruyzes es el que suelen emplear Laguna y Agüero: recurso a los sinónimos, definiciones breves introducidas por expresiones del tipo «que se parece a...», «semejante a...», etc. No obstante, en estos dos últimos autores las definiciones un poco más extensas y elaboradas adquieren un cierto protagonismo, sobre todo en Laguna, en el que alcanzan el 35\% del total, lo que constituye una proporción nada desdeñable para la época en que nos encontramos. Igualmente, se constata en ambos un esfuerzo por ofrecer, no tanto distintas posibilidades, acepciones posibles para un término, sino una única definición genérica del mismo. No les atrae, por ejemplo, incluir varias entradas con las diversas clases de antídotos que pueda haber - como hace Ruyzes-, sino tan solo la entrada antitodo, con su definición genérica. Esto podría indicar que existe en ellos un distinto tipo de interés lexicográfico y una diferente manera de plasmarlo en la práctica: no se trata ya de coleccionar formas y formas atestiguadas de un mismo término (en latín, árabe, griego y lenguas vernáculas), al estilo de los synonyma medievales, sino de ensayar nuevas 
posibilidades lexicográficas: olvidarse de lo particular para llegar a lo general; del peso de la tradición y de la costumbre acumulativa tan propia del medievo para buscar definiciones claras, sencillas y a ser posible sólo en castellano.

Que «sólo» lo hicieran para 100 o 200 voces, ni justifica la etiqueta que se le ha puesto a sus obras -índice, tabla, glosario-, ni justifica tampoco que después de conocer sus trabajos, se les prive del puesto meritorio que les corresponde en la historia de la lexicografía especializada del Renacimiento.

\section{REFERENCIAS BIBLIOGRÁFICAS}

Alonso y DE LOS RUYZeS DE FonTeChA, Juan (1606 [1999]): Diccionario de Juan Alonso y de los Ruyzes de Fontecha, estudio y edición crítica de M. P. Zabía Lasala, Madrid, Arco/Libros.

Blas Nistal, Cristina (2002): «La aportación del Doctor Laguna al desarrollo lexicográfico de los tecnicismos médicos: presentación y estudio del glosario incluido en la edición de la Materia Médica de Dioscórides», en M. Suárez Fernández y A. Veiga Rodríguez, coords., Historiografia lingüistica y gramática histórica: gramática y léxico, Madrid, Iberoamericana, pp. 147-156.

CARrera de la Red, Avelina (1997): «Dioscórides en la obra médica de E. A. de Nebrija», en Humanismo y pervivencia del Mundo Clásico. Homenaje a Luis Gil, Cádiz, Universidad de Cádiz-Ayuntamiento de Alcañiz, II.1, pp. 121-128.

(2001): Dictionarium medicum: el Diccionario médico de Elio Antonio de Nebri$j a$, introducción, edición y glosario de $\sim$, Salamanca, Universidad de Salamanca.

Castaño Almendral, Alfonso A. (1959): La obra quirúrgica de Bartolomé Hidalgo de Agüero, Salamanca, Seminario de Historia de la Medicina Española.

COROMINAS, Joan y José Antonio PASCUAL (1980-1991): Diccionario crítico etimológico castellano e hispánico, Madrid, Gredos.

Diccionario médico-biológico, histórico y etimológico [Dicciomed] (accesible en http://www.dicciomed.es/).

DuBler, César E. (1953-1959): La materia médica de Dioscórides, Barcelona, Tip. Emporium, 6 vols. 
GIL, Luis (1981): Panorama social del humanismo español (1500-1800), Madrid, Alhambra.

GóMEZ MoReno, Ángel (2000): «La resurrección de Dioscórides y la edición comentada de Laguna», Criticón, 79, pp. 107-122.

GonZÁlez IGLeSIAS, Julio (1994): Historia de la Odontoestomatología Española, Madrid, Avances.

GonZÁLEZ MANJARRÉs, Miguel Ángel (2000): Andrés Laguna y el humanismo médico: estudio filológico, Valladolid, Junta de Castilla y León.

Guerrero Ramos, Gloria (1992): «Anotaciones de Nebrija a Dioscórides. Voces españolas», BRAE, LXXII, 255, pp. 7-50.

GutiÉRREZ Rodilla, Bertha M. (1996): «Construcción y fuentes utilizadas para los términos médicos en el Diccionario de Autoridades», Revista de Lexicografia, I, pp. 149162.

(1999): La constitución de la lexicografía médica moderna en España, A Coruña, Toxosoutos.

(2001): «Los textos médicos romances en el Renacimiento castellano», en J. L. García Hourcade y J. M. Moreno Yuste, coords., Andrés Laguna. Humanismo, ciencia y política en la Europa Renacentista, Valladolid, Junta de Castilla y León, pp. 529-538.

(2007): La esforzada reelaboración del saber. Repertorios médicos de interés lexicográfico anteriores a la imprenta, San Millán de la Cogolla, Cilengua.

- y Carlos GARCÍA JÁUREGUI (en prensa): «Repertorios lexicográficos 'escondidos' del Renacimiento: el glosario médico de Bartolomé Hidalgo de Agüero», III Jornadas de la Red Temática "Lengua y Ciencia” [Coimbra, 2009].

HERRERA, $\mathrm{M}^{\mathrm{a}}$ Teresa, dir. (1996): Diccionario español de textos médicos antiguos [DETEMA], Madrid, Arco/Libros.

HidALGO DE AGÜERO, Bartolomé (1604): Thesoro de la verdadera Cirugía y vía particular contra la común, Sevilla, Francisco Pérez.

H INOJO ANDRÉS, Gregorio (2006): «Nebrija y el desarrollo del léxico científico en latín», Panacea. Boletín de Medicina y Traducción, 7, pp. 123-129.

Laguna, Andrés (1555): Pedacio Dioscorides Anazarbeo, acerca de la materia medicinal, $y$ de los venenos mortiferos, traduzido de lengua Griega, en la vulgar Castellana, e 
illustrado con claras y substanciales annotationes, y con las figuras de innumeras plantas exquisitas y raras [...], Amberes, Juan Latio.

LóPEZ PiÑERO, José María (1983): «Hidalgo de Agüero, Bartolomé», en J. M. López Piñero, T. F. Glick, V. Navarro y E. Portela, Diccionario histórico de la ciencia moderna en España, Barcelona, Península, pp. 456-458.

Marcovecchio, Enrico (1993): Dizionario Etimologico Storico dei Termini Medici, Firenze, Festina-Lente.

NebriJa, Elio Antonio de (1516): Lexicon Dioscoridis. Índice a la edición de Dioscórides de J. de la Ruelle (Pedacii Dioscoridis Anazarbei de Medicinali materia liber primus [...] Explicitum est Dioscorides insigne hoc opus de medicinali materia Ioanne Ruellio Suessonensi ex graeco in latinum sermonem interprete), Compluti Carpetanie, Arnaldi Guillelmi.

Nieto Jiménez, Lidio y Manuel Alvar EzQuerRa (2007): Nuevo Tesoro Lexicográfico del Español (s. XIV-1726), Madrid, Arco/Libros, 11 vols.

Real Academia Española (1726-1739): Diccionario de Autoridades, Madrid, Francisco del Hierro.

SÁNCHEZ GRANJEL, Luis (1956): Bartolomé Hidalgo de Agüero, Madrid, s. 1. 